\title{
Contrabandistas de migrantes a pequeña escala de Tamaulipas, México ${ }^{1}$
}

\author{
Simón Pedro Izcara Palacios*
}

\section{Resumen}

Los contrabandistas de indocumentados que operan a pequeña escala y a tiempo parcial están unidos por lazos a la propia comunidad migrante. Ellos trabajan en los Estados Unidos durante varios meses para regresar de modo periódico a sus comunidades para organizar con la ayuda de varios asistentes un pequeño grupo de migrantes que son transportados hasta el lugar de destino de los propios polleros. Este artículo analiza el contrabando a pequeña escala realizado por polleros de Tamaulipas, que transportan hasta los Estados Unidos, una o muy pocas veces al año, migrantes de sus lugares de origen $\mathrm{u}$ otras áreas vecinas para que trabajen en el sector agrario.

\begin{abstract}
Small-scale part-time smugglers are embedded in the migrant community itself. They work in the United States for several months before returning to their place of origin to organize, with the help of several assistants, a small group of migrants, who are transported where the coyotes themselves are going. This article analyses small-scale smuggling carried out by Tamaulipas' polleros, who transport to the United States, one or a few times per year, migrants from their hometowns or other neighboring areas in order to be employed in the farming sector.
\end{abstract}

Palabras clave: polleros, agricultura, jornaleros, migrantes indocumentados, Tamaulipas, Estados Unidos.

Key words: smugglers, farming, farm workers, undocumented migrants, Tamaulipas, United States.

* Doctor en Sociología por la Universidad Complutense de Madrid, España. Profesor-investigador en la Universidad Autónoma de Tamaulipas.

1 Quisiera expresar mi agradecimiento a la SEP/Conacyt por el apoyo recibido a través del Proyecto 155901 titulado "Coyotaje y migración indocumentada en Tamaulipas". 
os deficientes estándares sociolaborales existentes en el sector agrario estadounidense han generado la huida tanto de la mano de obra autóctona como de aquellos trabajadores foráneos que regularizan su situación laboral; por lo tanto, la agricultura constituye un sector dependiente de la disposición de mano de obra indocumentada proveniente principalmente de México.

Hasta hace dos décadas los jornaleros tamaulipecos no encontraban muchas dificultades para cruzar la frontera y trabajar en el país vecino, donde los salarios eran muy superiores a los recibidos en sus comunidades de origen. Sin embargo, el cambio de la política migratoria estadounidense hacia un reforzamiento de la vigilancia fronteriza hizo que fuese más complicado cruzar la frontera. Es por ello que para poder seguir abasteciéndose de mano de obra barata los empleadores tuvieron que tomar una posición más activa en el reclutamiento de trabajadores indocumentados.

Arango (2003: 15; 2000: 290) y Massey et al. (2009: 29) han argumentado que en la actualidad las corrientes migratorias no tienen su origen en prácticas de reclutamiento; sino que los procesos migratorios se mueven de modo autónomo, a través de redes sociales, de modo que más que ser la demanda lo que impulsa la migración, la oferta de trabajadores migratorios crea su propia demanda. Sin embargo, muchos empleadores estadounidenses han tenido que financiar y construir redes de contrabando de indocumentados, que operan a pequeña escala, para reclutar a sus trabajadores.

El objetivo de este artículo es describir a los contrabandistas de indocumentados $^{2}$ a pequeña escala de Tamaulipas que son empleados por empresarios agrarios estadounidenses. La relevancia del tema radica en que durante las dos últimas décadas tanto el discurso oficial como el académico han insistido en un desplazamiento del contrabando de indocumentados a pequeña escala por el tráfico de inmigrantes operado por redes criminales. Los contrabandistas de indocumentados son descritos por las autoridades y medios de comunicación como personas despiadadas asociadas al crimen organizado, que guiadas por el ánimo de lucro causan un grave daño a los inmigrantes. El uso de una metodología cualitativa permitió que éstos pudiesen narrar sus vivencias y experiencias a través de un formato flexible, que no presenta la rigidez y hermetismo de las encuestas y cuestionarios.

2 En este artículo los términos "pollero", "coyote", "contrabandista de migrantes", "contrabando de inmigrantes" y "coyotaje" son utilizados de modo indistinto. 
Este artículo estudia el contrabando de inmigrantes a pequeña escala realizado por polleros de Tamaulipas que reclutan mano de obra indocumentada para empresarios agrarios de Estados Unidos. En primer lugar analizo la hipótesis del declive del contrabando de migrantes a pequeña escala; a continuación examino la biografía de 40 contrabandistas de indocumentados tamaulipecos que operan a pequeña escala; después describo la construcción de una alianza entre éstos y sus empleadores que determinará que los primeros se dediquen al contrabando de inmigrantes, y finalmente explico la presencia y actuación de las redes delictivas en el contrabando de migrantes a pequeña escala en Tamaulipas.

\section{Metodología}

Esta investigación está fundamentada en un enfoque metodológico cualitativo. La técnica que se aplicó para recabar el material discursivo fue la entrevista en profundidad. Las entrevistas fueron conducidas con un guión abierto que fue acomodándose a la experiencia de cada entrevistado; por lo tanto, no en todas las entrevistas se abordaron las mismas preguntas.

El trabajo de campo se llevó a cabo entre los meses de abril de 2008 y diciembre de 2011 y fueron entrevistados 40 polleros tamaulipecos que operaban a tiempo parcial y formaban parte de la corriente migratoria (es decir, trabajaban como jornaleros para un empleador estadounidense y periódicamente regresaban a Tamaulipas para reclutar migrantes indocumentados que ellos mismos conducían hasta Estados Unidos). La muestra se construyó a partir de dos elementos. Por una parte, se buscó a contrabandistas de migrantes que manifestasen una disposición a hablar de su actividad de modo extendido en una entrevista que tendría una duración superior a una hora, y que sería retomada en un segundo momento para esclarecer cuestiones que en el primer encuentro hubieran quedado confusas. Por otra parte, se persiguió que la muestra englobase a polleros de toda la geografía tamaulipeca.

La muestra fue construida a través del muestreo en cadena; es decir, los entrevistados fueron contactados a partir de la ayuda de informantes que conocían a gente que se dedicaba a facilitar el cruce de la frontera a migrantes sin documentos. A medida que nuevos individuos se integraban en la muestra, éstos sirvieron de enlace para captar nuevos informantes.

Las entrevistas se realizaron en 14 municipios representativos de la geografía de Tamaulipas: el noroeste (Mier), el noreste (Reynosa, Matamoros y San Fernando), el suroeste (Tula, Jaumave, Ocampo, Palmillas y 
Miquihuana), el sureste (El Mante), el centro-oeste (Victoria, Hidalgo y San Carlos) y el centro-este (Abasolo). El tamaño de la muestra obedeció a una saturación del campo de diferencias en la producción discursiva de los hablantes. Cuando los discursos de los entrevistados se tornaron redundantes se dio por concluido el proceso de acopio de información.

Todos los entrevistados se dedicaban al contrabando de indocumentados cuando fueron entrevistados, excepto Tomás, que abandonó esta actividad en 1993; Abelardo, que lo hizo en 1997, y Vicente, que dejó de facilitar el cruce a trabajadores migratorios en el 2003. En el anexo 1 aparece la presentación de cada uno de los entrevistados.

\section{La hipótesis del declive del contrabando de migrantes a pequeña escala}

López Castro (1997) en un estudio sobre el contrabando de indocumentados en México contrapone los coyotes locales o contrabandistas a pequeña escala al negocio del coyotaje fronterizo, y define a los primeros como personas que operan a través de redes muy simples, que transportan a cinco o seis migrantes que proceden de la localidad de origen del propio coyote y se dirigen al mismo sitio que éste, que trabaja a tiempo parcial y cobra tarifas reducidas. Kyle y Dale (2001: 32) hablan de "esquemas de exportación de migrantes" que contraponen a las "operaciones de importación de migrantes", y describen las primeras como estructuras oportunistas e irregulares, que operan a tiempo parcial.

El discurso oficial sobre el desarrollo del coyotaje en la frontera suroeste de los Estados Unidos sostiene que a partir de los años noventa, como resultado de una política migratoria de control de la frontera, el contrabando de indocumentados a pequeña escala ha ido languideciendo, para ser sustituido por el tráfico de personas a mayor escala operado por redes más sofisticadas. Esto significa que se estaría produciendo una sustitución del contrabando de indocumentados, que viola los derechos de los estados, por el tráfico de personas, que representa una violación a los derechos humanos (Vayrynen, 2003: 1). En un informe del Subcomité de investigaciones del Comité de Seguridad Nacional de la Casa de Representantes el contrabando de indocumentados se le describe como un negocio que ha pasado a manos de los cárteles de la droga, que utilizan sus corredores para transportar migrantes, drogas, y potencialmente a terroristas y armas de destrucción masiva (HCHS, 2006: 28-30). El contrabando de migrantes ya no es visto como una actividad poco 
estructurada y manejada a nivel local, sino como un negocio siniestro, operado por criminales (HCHS, 2006: 18).

El discurso académico también subraya que se ha producido un declive del contrabando de migrantes a pequeña escala. Alonso Meneses (2010: 29) señala que todavía pueden existir coyotes de confianza que pertenecen a la comunidad de migrantes; pero esto lo considera más una cosa del pasado, y define el coyotaje como un negocio que ha atraído a organizaciones mafiosas. Martínez (2010: 141) establece una distinción entre coyotes y guías, describe a los primeros como peligrosos, timadores y secuestradores, y habla de un declive de la figura del coyote-amigo. Algunos estudios establecen una conexión entre la militarización de la frontera y una mayor conexión del contrabando de migrantes con los cárteles de las drogas y con organizaciones criminales que disponen de las conexiones necesarias para evadir la vigilancia de la frontera (Slack y Whiteford, 2010: 88; Andreas, 2006: 65). Aunque, mientras Andreas (2003: 3 y 2006: 67) sostiene que la política migratoria estadounidense tuvo el efecto no buscado de enriquecer a los contrabandistas y fortalecer al crimen organizado sin lograr su objetivo de detener el flujo migratorio irregular, Kyle y Dale (2001: 31) argumentan que el gobierno de los Estados Unidos habría perseguido de forma deliberada destruir el coyotaje a pequeña escala para favorecer al crimen organizado, porque el primero, que es más caótico y opera a tiempo parcial, es más difícil de combatir que el último, que es más organizado y opera a gran escala. ${ }^{3}$

En consonancia con la hipótesis del declive del contrabando de migrantes a pequeña escala, a partir de las dos últimas décadas se ha diseminado una opinión generalizada que describe a los coyotes como personas movidas únicamente por el afán de lucro, que tienen intereses contrapuestos a los de sus clientes. El discurso oficial sostiene que los coyotes desprecian las vidas de los migrantes (HCHS, 2006: 17). Los medios de comunicación les describen en el mejor de los casos como un mal necesario. El discurso académico también presenta una imagen negativa de los polleros. Según Guerette y Clarke (2005) la avaricia de los contrabandistas de indocumentados conduce frecuentemente al abandono y muerte de muchos migrantes. García Vázquez et al. (2007: 104) señalan que muchos migrantes mueren porque son abandonados por los polleros. Addiechi (2005: 174) explica que con frecuencia los migrantes son abandonados en lugares desérticos donde sus probabilidades de supervivencia son escasas. Slack y Whiteford (2010:

3 Asimismo, Zhang (2010: 13) señala que las organizaciones que tienen una clara estructura jerárquica son más fáciles de remover que aquéllas más desestructuradas. 
90) también culpan a los polleros por el asalto y abandono de migrantes en el desierto.

Como contraste, un grupo más reducido de académicos defiende la hipótesis del predominio del contrabando de indocumentados a pequeña escala. Zhang (2010: 13) subraya que esta actividad es conducida principalmente por organizaciones poco estructuradas, pequeñas y casuales. ${ }^{4}$ Sharma (2005: 94) señala que el contrabando de indocumentados no aparece ligado a grupos criminales, y es operado por pequeños empresarios. Spener (2008 y 2009) afirma que el reforzamiento del control fronterizo no ha alterado la estructura del coyotaje, que sigue dominado por polleros que operan a pequeña escala. Según Spener (2004: 35) la visión oficial que habla de una sofisticación de las redes de contrabando de indocumentados y de una participación del crimen organizado en las mismas estaría relacionada con un porcentaje mayor de denuncias hacia los coyotes que cometieron abusos, hacia los cuales los migrantes no tienen un sentido de lealtad u obligación. Por el contrario, un menor número de denuncias hacia aquellos coyotes que forman parte de la corriente migratoria y mantienen estrechos lazos con los migrantes, conduciría a una falsa impresión de que el coyotaje a pequeña escala habría decrecido.

De acuerdo con esta hipótesis los coyotes y sus clientes tendrían unos mismos intereses. Kyle y Liand (2001: 23) señalan que debe existir un lazo de confianza entre ambos. Sharma (2003: 60) define a los contrabandistas como las personas que más ayudan a los migrantes. Spener (2009) les describe como partícipes de una alianza estratégica de resistencia frente a la estructura represiva del apartheid global que se pone en práctica en las fronteras de los estados. Para Spener (2008:144) los migrantes y sus coyotes "comparten intereses y objetivos comunes en sus batallas cotidianas con el apartheid en la frontera", que opera restringiendo el movimiento físico, negando derechos a los migrantes y haciéndoles vulnerables a la explotación. Asimismo, Mestries Benquet (2005: 1036) en un estudio sobre la emigración internacional en una zona cafetera y cañera de Veracruz afirma que la mayor parte de los polleros son de la región, son conocidos de los migrantes y existen lazos de confianza entre ambos.

La negligencia de los coyotes podría medirse a través de las muertes de migrantes en la frontera. Si los primeros abusasen de los últimos y les abandonasen en el desierto el número de muertes debería ser muy elevado. Las autoridades atribuyen las muertes de migrantes a la actitud de los coyo-

4 Aunque este autor también ha argumentado que el contrabando de indocumentados se ha convertido en una actividad más organizada (Zhang, 2007: 62). 
tes, que abandonan a sus clientes y les conducen por áreas peligrosas. ${ }^{5} \mathrm{Sin}$ embargo, algunos autores han minimizado el incremento de la mortalidad en la frontera. Fuentes y García (2009: 89) se sorprenden por los bajos porcentajes de abuso y abandono registrados por los migrantes tlacuitapeños conducidos por polleros. Zhang (2007: 66) señala que un desplazamiento de los movimientos migratorios hacia rutas más inhóspitas no aparece asociado a un incremento de las muertes por exposición a condiciones climáticas extremas. Nevins (2003: 173) afirma que las muertes en la frontera no son algo nuevo, y que no son muy superiores a las registradas cuando no existía tanta vigilancia, y Spener (2004: 298) subraya que la mayoría de los migrantes llegan a sus destinos sanos y salvos.

\section{Los polleros tamaulipecos que operan a pequeña escala}

En muchas de las comunidades rurales tamaulipecas residen personas que trabajan a tiempo parcial conduciendo a gente de su entorno geográfico hacia los Estados Unidos para ser empleados en el sector agrario (Izcara Palacios, 2011: 48). Éstos provienen de familias de reducidos recursos, que emigraron sin documentos a los Estados Unidos, debido a la falta de oportunidades económicas en sus lugares de origen. En el país vecino se esforzaron por abrirse paso y agradar a sus patrones, con quienes tejieron lazos de confianza. La relación de amistad forjada entre éstos y sus empleadores finalmente conduciría a que se dedicasen a transportar a los Estados Unidos personas de su entorno a cambio de una remuneración económica.

\section{Una incursión temprana en el ámbito laboral}

El elemento más característico de la biografía de los entrevistados es su inserción temprana en el ámbito laboral. Todos proceden de familias de bajos recursos. Algunos provienen de hogares monoparentales (son hijos de madres solteras, su padre murió joven, desapareció, o éste les abandonó), y la mayoría son hijos de campesinos empobrecidos o jornaleros subempleados. Además, casi todos proceden de familias numerosas, por

5 En una declaración conjunta realizada el 14 de mayo de 2001 sobre la muerte de 14 inmigrantes en el desierto de Arizona, los gobiernos de Estados Unidos y México declararon que los contrabandistas de indocumentados eran responsables por poner las vidas de los migrantes en riesgo (Governments of the United States and Mexico, 2001). 
lo que muy pronto tuvieron que contribuir con su trabajo al sostenimiento de la economía familiar.

La inserción temprana en el ámbito laboral significó que la mayor parte de los entrevistados tuviesen que abandonar los estudios para dejar de ser una carga para sus familias. Melchor, hijo de un ejidatario de una comunidad rural de Tula señalaba que únicamente pudo estudiar hasta el tercer grado de primaria debido a que su padre, desde que cumplió seis años, le hacía salir de la escuela para que le ayudase con las tareas del campo: "tendría como unos 6 años porque recuerdo que empezaba a ir a la escuela, y en ocasiones no me dejaban ir porque tenía que echarle la mano a mi papá". Asimismo, Roberto, hijo de otro campesino de un ejido de Tula, apenas pudo concluir la educación primaria porque como él decía "aquí uno empieza a trabajar desde que está chiquillo; a nosotros, a mí y a mis hermanos, mi papá nos ponía a trabajar en la huerta, así no más salíamos de la escuela y nos íbamos a ayudarle, desde que uno tiene como ocho años". El haber visto truncada su educación por falta de recursos dejó una marca en muchos de ellos; de modo que cuando tuvieron dinero lo invirtieron principalmente en la educación de sus hijos o hermanos. Ellos no dejaron que sus hijos abandonasen la escuela, y cuando éstos fueron mayores de edad les instaron a estudiar una carrera universitaria, en muchos casos en una institución prestigiosa y costosa.

Aquellos que crecieron en un hogar monoparental tuvieron una niñez más problemática. Oliver relataba que a los 7 años de edad su padre les abandonó, por lo que se trasladó con su madre y seis hermanas menores de edad de un ejido de Palmillas a Ciudad Victoria. Aquí se dedicó a cargar maletas en la central camionera para alimentar a sus hermanas, por eso nunca pudo ir a la escuela: "teníamos que trabajar porque con todas las boquitas que teníamos en la casa; ésas sólo pedían de comer y lloraban". Cuando la madre se vuelve a casar, su situación no mejora; muy al contrario, pasan a ser explotados por un padrastro abusivo. Como relataba Antonio: "tenía ocho, estaba chico, pero ya trabajaba, tenía que ayudarle a él (su padrastro), pues vivíamos en su casa; era bueno conmigo sólo que con mi madre se pasaba, le daba unas buenas golpizas".

Expresiones como: "tenía como 6 o 7 años de edad cuando ya me llevaba mi padre, que en paz descanse, a la parcela" (Braulio); “desde pequeño ayudé en los trabajos de la casa a papá" (Miguel); "desde niño mi padre me enseñó a trabajar en el campo" (Ramiro); "se vino unas rachas de esas malas que hay, y tuve que salir a trabajar con mi padre a la sierra" (Gerardo); "yo empecé a trabajar como a los ocho años, porque me llevaba mi papa con mis hermanos al monte" (Rafael); "desde peques nos enseñamos a trabajar 
en los trabajos duros" (Natalio) o "siempre trabajé desde que tenía como unos 7 años" (Misael) hacen referencia a una infancia áspera.

El recuerdo más amargo de la infancia no es el trabajo duro; sino el hambre. Ellos señalaban en las entrevistas que el problema diario más acuciante sufrido por sus familias era cómo alimentar tantas bocas. Óscar, que procede de una familia de 12 hermanos, señalaba: "nos criamos con masa y agua revuelta". Él recordaba que cuando su padre tenía trabajo comían dos veces al día; pero cuando estaba desempleado apenas comían. Asimismo, Osvaldo, que procede de una familia de nueve hermanos, decía: "tenía una hermana de cinco años, estaba chica, y ella se murió por desnutrición, porque no comíamos".

Aquellos polleros que crecieron en entornos más favorables económicamente, porque el padre emigró a los Estados Unidos y disponían de mayores recursos económicos, relataban una infancia caracterizada por la asunción de un rol laboral de adultos. Prudencio decía que a la edad de diez años "iba a la escuela y ya no fui, porque muchos de los que íbamos ya no fuimos porque se iban los papás para el otro lado". Cuando él señalaba que muchos niños de su localidad (un ejido de Jaumave) dejaron de ir a la escuela porque sus padres fueron a trabajar a los Estados Unidos, hacía referencia a que ellos tuvieron que asumir las tareas que realizaba el cabeza de familia en la explotación doméstica, lo cual era incompatible con la continuación de su educación escolar. Asimismo, Reinaldo afirmaba que debido a que su padre y sus dos hermanos mayores trabajaban en una plantación tabaquera de Carolina del Norte, él, que era el hijo menor: "tenía que hacer aquí lo que él (el padre) hacía antes de irse". Él afirmaba que, al no encontrarse su padre ni sus hermanos mayores, tuvo que asumir "la responsabilidad de un padre de familia".

Dos tercios de los entrevistados comenzaron a trabajar antes de cumplir diez años de edad y pocos pudieron estudiar más allá de la primaria (véase la tabla 1). El hecho de crecer en un entorno caracterizado por estrecheces económicas truncó su educación y les condujo a una pronta incorporación al ámbito laboral; pero también inculcó en muchos de ellos una ética del trabajo, una actitud de servicio y disposición ante las demandas de sus futuros empleadores; además, de una capacidad elevada de asumir riesgos. La adquisición de estos valores sería fundamental para el ejercicio del contrabando de indocumentados. 


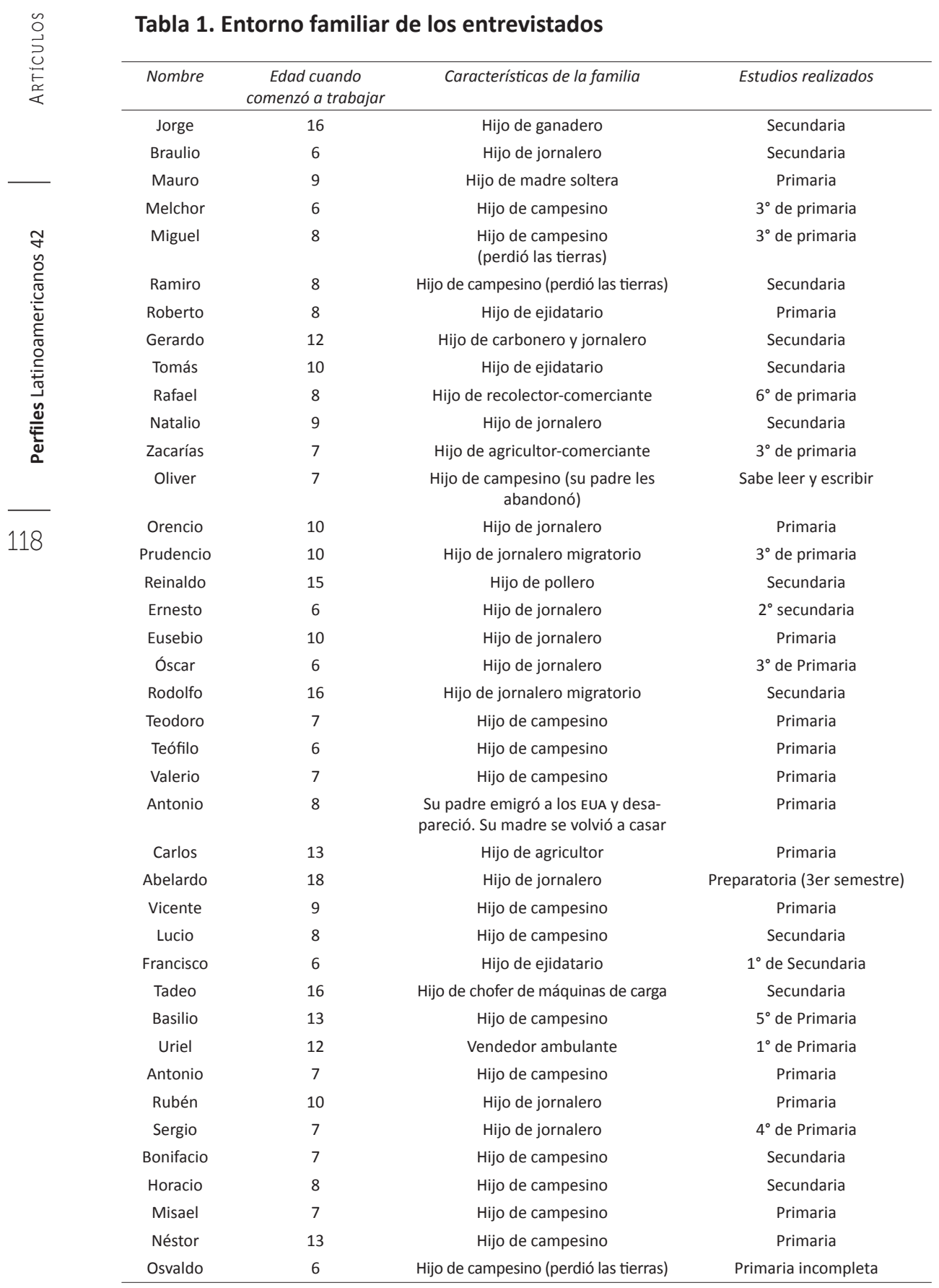

Fuente: Elaboración propia. 


\section{La construcción de una alianza con los empleadores}

Casi todos los entrevistados tuvieron que asumir muy pronto un rol de adultos para sostener la economía familiar. En algunos casos por ser el único varón de la familia (como Oliver); en otros porque el padre emigró (como Prudencio, Reinaldo o Rodolfo); otras veces por ser el hermano mayor, y en otras ocasiones por proceder de familias campesinas donde es común que los hijos varones ayuden al padre desde una edad muy temprana. Como decía Francisco "como a los seis años empecé a trabajar [...] a los hombres se les enseña a trabajar desde bien chicos, por eso los hombres de rancho son más trabajadores que los de la ciudad".

Uno de los aspectos más sobresalientes del discurso de los entrevistados es la interiorización de la responsabilidad de mantener a sus familias. Ellos se educaron bajo el axioma de tener que sacrificarse por la familia. Sin embargo, el medio rural tamaulipeco ofrece escasas oportunidades económicas a los jóvenes no cualificados (Izcara Palacios, 2010b: 462); es por ello que los entrevistados se arriesgaron a emigrar de modo subrepticio a los Estados Unidos; en muchas ocasiones siendo menores de edad (como lo hicieron Braulio, Miguel, Roberto, Rafael, Natalio, Zacarías, Oliver, Reinaldo, Ernesto, Antonio, Rubén, Sergio, Bonifacio y Osvaldo). Después de cruzar la frontera encontraron empleo en la agricultura, una actividad en la cual tenían mucha experiencia debido a su procedencia rural y pertenencia a familias campesinas. Osvaldo, que cruzó la frontera en 1981, cuando sólo tenía 10 años de edad, acompañado por sus hermanos de 15 y 19 años, obtuvo empleo en un rancho de Texas; aunque únicamente cuatro años más tarde su patrón le ofreció un salario completo, cuando comprobó que rendía como un adulto, era disciplinado y no descansaba los domingos.

En Estados Unidos demostraron una sobresaliente capacidad para el trabajo y una disposición para realizar cualquier tipo de actividad. Tomás señalaba que desde que llegó en 1983, cuando tenía 20 años, a un rancho de Carolina del Norte, se ganó la confianza de su patrón debido a su forma de trabajar "siempre he trabajado bien, el trabajo es quien habla por ti [...] Cuando trabajaba de peón le ayudaba mucho al patrón, y luego, cuando los amigos de mi patrón necesitaban ayuda, él me mandaba para que les apoyara, y siempre les respondí con el trabajo bien hecho". Esta predisposición a hacer cualquier cosa aparecía expresada por Óscar: "yo he sabido ganármelo con trabajo [...] saben que yo respondo por lo que se mande". Teófilo manifestaba del siguiente modo su fidelidad y disposición permanente hacia su empleador: "con el tiempo que trabajé con él, así trabajaba 
bien yo, y él me reconoció así, cuando necesitaba cosas extras, pues me hablaba a mí, sabía que no decía que no".

La capacidad de los entrevistados para el trabajo duro, el orgullo por el trabajo bien hecho, un sentido de la lealtad y un interés por agradar a sus patrones; además de una versatilidad para hacer tareas diversas, pronto llamó la atención de sus empleadores, con quienes poco a poco se solidificó un vínculo de afecto y respeto mutuo. En las siguientes expresiones aparece una referencia a la forja de una relación de confianza y amistad entre los entrevistados y su empleador, hasta el punto de que muchos polleros consideran a sus patrones como parte de su familia:

"El patrón ya tenía confianza conmigo" (Melchor).

"Me tiene confianza él a mí y yo a él" (Gerardo).

"Me tuvieron confianza al ver los resultados que obtenía" (Óscar).

"Somos amigos, nos tenemos confianza, y nos ayudamos para lo que se necesite" (Antonio).

"Me he ganado la confianza; siempre con trabajo" (Carlos).

"Con el tiempo me fue dando confianza, confiaba en mí, y así empezó esta amistad" (Teodoro).

"Los patrones son casi como familia mía; yo llego allá y es como mi casa" (Basilio).

"Con él hay confianza, además que estoy bien ahí trabajando" (Sergio).

“Tengo de conocerlo unos 25 años, desde que yo era muy joven que me conoce, y por eso me tiene aprecio y confianza, me trata bien, es bueno, a veces cuando viene aquí a México llega a mi casa en lugar de llegar a un hotel y no porque no tenga para pagar, sólo que él conoce a mi familia y también la quiere, se siente muy a gusto aquí" (Bonifacio).

"La confianza que me tiene me la he ganado con mi comportamiento" (Misael).

"Somos amigos y nos llevamos bien, trato de hacer el trabajo a la perfección" (Néstor).

En casi todas las entrevistas los polleros manifiestan un profundo agradecimiento hacia sus patrones. La construcción de una alianza con los empleadores basada en la amistad y la confianza determinará más adelante que los primeros se dediquen al contrabando de migrantes. 


\section{El inicio en el contrabando de migrantes}

Los entrevistados se iniciaron en el contrabando de migrantes de modo fortuito. Únicamente Vicente trabajó como pollero desde el primer momento que emigró a los Estados Unidos; ${ }^{6}$ en el resto de los casos el espacio temporal transcurrido entre la primera vez que emigraron sin documentos al país del norte y cuando iniciaron su actividad como polleros alcanza una media de casi ocho años (véase la tabla 2). Durante estos años regresaron una o varias veces a Tamaulipas. El haber emigrado previamente sin documentos a los Estados Unidos les permitió conocer la geografía de la frontera: aprendieron por dónde cruzar y cómo esquivar a la Patrulla Fronteriza.

Tabla 2. Años transcurridos desde la primera vez que emigraron sin documentos a los Estados Unidos y el inicio de su actividad como polleros

\begin{tabular}{cc|c}
$\begin{array}{c}\text { Número de años } \\
\text { transcurridos }\end{array}$ & Frecuencia & Media \\
\hline 0 & 1 & \\
1 & 2 & \\
2 & 3 & \\
3 & 2 & 7.72 \\
4 & 4 & \\
5 & 4 & \\
6 & 5 & \\
7 & 2 & \\
8 & 1 & \\
9 & 1 & \\
10 & 3 & \\
11 & 3 & \\
12 & 2 & \\
14 & 2 & \\
16 & 2 & \\
18 & 1 & \\
25 & 1 & \\
& & \\
\hline
\end{tabular}

Fuente: Elaboración propia.

6 En 1995, cuando él tenía 35 años, un pollero, amigo suyo, le invitó a ir al rancho donde trabajaba en Texas, y desde un principio le ayudó a facilitar el cruce de la frontera a otros migrantes. Los dos estuvieron trabajando así durante 8 años; cruzaban dos veces al año la frontera, pero la mayor parte de los ingresos los obtenían del trabajo agrario. Como decía Vicente el contrabando de migrantes únicamente suponía un dinero extra "un amigo que conocí me metió en eso; pero no era de siempre, ahí me ganaba un dinero extra". 
La idea de dedicarse a facilitar el cruce de la frontera a otros paisanos en muchos casos no surgió de su empleador; pero, siempre fue alentada por éste. Muchos de los entrevistados se ajustan al perfil de antiguos empleados que regresaron a Tamaulipas debido a que fueron interceptados por las autoridades migratorias y deportados de Estados Unidos (como Mauro o Ernesto), a la añoranza de la familia (como Jorge o Braulio), o sencillamente porque pudieron reunir un umbral de ahorros y ya no quisieron permanecer más tiempo fuera de su país (Izcara Palacios, 2010c: 612).

Cuando regresaron a Tamaulipas algunos invirtieron sus ahorros en la compra de un vehículo, una vivienda o tierras; otros gastaron todos sus ahorros. En algunos casos no pasó mucho tiempo hasta que se quedaron sin nada y se vieron en la necesidad de volver a cruzar la frontera porque encontraron los empleos locales poco atractivos. Aunque, esta vez no contrataron los servicios de un pollero, pero tampoco lo hicieron solos; debido a que conocían los entresijos del cruce fronterizo, ellos mismos se convirtieron en líderes de un grupo de paisanos que también querían trabajar en el país vecino. En esta primera ocasión ayudaron a pasar la frontera a otras personas muy cercanas a ellos (parientes, amigos o conocidos de la misma localidad), y cruzaron con un reducido número de acompañantes (dos o tres personas). La buena relación existente entre éstos y su antiguo empleador hizo que se animasen a cruzar con más personas, porque sabían que éste les daría empleos a todos. Una vez que traspasaron la frontera y llegaron hasta el lugar donde habían trabajado anteriormente, su antiguo patrón no únicamente les recibió con los brazos abiertos, sino que les alentó a seguir desarrollando esta actividad en el futuro. Relatos parecidos a los siguientes se repiten en muchas entrevistas:

“Cuando hablé con el patrón, le dije lo que había hecho y él me dijo: 'no es mala idea, si ya conoces el camino hasta Houston, tráetelos y yo mando por ustedes y nos arreglamos'. De lo que les cobramos él también quería mochada; entonces, ese fue el trato, yo me los llevo hasta Houston" (Jorge) .

"Cuando me fui por segunda vez invité a unos chavos de por aquí y nos fue bien, llegamos sanos y salvos y hablé con el patrón y le dije que si les daba trabajo que yo los llevaba y él les dijo que sí; así empecé con dos y luego para el tercer año que me iba la raza ya sabía que yo llevaba gente, y así cada vez más gente se entera y llevo y gano por llevarlos" (Mauro). 
No todos los jornaleros que regresaron a los Estados Unidos acarreando a otros paisanos lo hicieron por iniciativa propia. En algunos casos el dinero ahorrado durante los años que trabajaron en el país vecino les permitió llevar una vida relativamente cómoda en Tamaulipas; sin embargo, pronto fueron apremiados por su antiguo patrón para que retornasen al país del norte, debido a que éste sufría una situación de escasez de mano de obra y ellos eran trabajadores muy eficientes. En un principio éste les pediría que regresasen solos; pero su empleador nunca tendría inconveniente en que retornasen guiando a otros paisanos. Es más, cuando ellos le propusieron la idea de ir con otras personas de su comunidad, el patrón, apremiado por la falta de brazos, les incitaría a que le llevasen a más gente; además, se comprometería a cubrir todos los gastos. Como señalaba Melchor:

“Me encargó que si podía llevarme a alguien eran bien recibidos. Yo ya había cruzado la frontera de mojado pero no con gente [...]; pero, me aventé a ver qué pasaba, y pasé con ellos hasta allá, hasta donde él me había dicho que me recogerían allá a las 5 de la madrugada, y te recogen, y de ahí nos llevaron a Houston, y de Houston para la Florida".

Otros comentaban que se iniciaron en el contrabando de migrantes por la necesidad de sacar de un apuro a su patrón. Algunos contrabandistas de indocumentados aparecían tan apegados a su empleador que llegaban a hacer suyas las preocupaciones de éste. Uno de los entrevistados manifestaba que él se hizo pollero porque a comienzos del año 1997, cuando regresó a Estados Unidos después de pasar la navidad en Tamaulipas, encontró a su empleador, un empresario agrario de Luisiana, enormemente preocupado porque se acercaba la época de la siembra y no disponía de suficientes trabajadores. En noviembre del año 1996 muchos de sus trabajadores habían retornado a México; pero después de Año Nuevo no regresaron. Al no disponer de suficientes brazos, no se podían comenzar las labores de siembra, y si esta actividad no se realizaba a tiempo no habría cosecha. Es por ello que Gerardo decidió arriesgarse por su patrón, para suministrarle la mano de obra que necesitaba. La repetición en el siguiente fragmento de la expresión: "no se mortifique" hace referencia a una muestra de compasión de este jornalero hacia su patrón:

"Cuando yo me vine se vinieron varios que sólo venían a pasar la navidad, y no volvieron, y yo sí volví, y el patrón me dice: qué voy a hacer ahora, ya que tengo el trabajo parado [...] Yo, al ver tan apurado 
a mi patrón, le dije: no se mortifique; mire, podemos hacer esto, allá de donde yo soy hay gente que quiere venir a trabajar acá, yo puedo ir y la invito para que venga, y así sacamos el trabajo y listo, no se mortifique, y él aceptó y me dijo: 'si tú la traes, mando al capataz que vaya a traerlos', y así fue, me dio dinero, vine y le llevé la gente”.

Francisco, que trabajó desde el 2003 hasta diciembre de 2006 en una plantación de tabaco de Virginia, relataba una situación similar:

“El patrón perdía mucho dinero en la cosecha y luego se echaba a perder por falta de mano de obra [...] por eso, cuando yo me vine para México, ya estando yo aquí en mi casa el patrón me habló y me dijo que me facilitaría todo lo que necesitara si le conseguía gente para trabajar y lo hice, la conseguí y me fui, se la llevé y a la temporada me vine porque sólo iba a eso, pero como me había ido bien pues sólo vine y lleve más gente y regresé".

En los Estados Unidos la mayor parte de la mano de obra asalariada agraria es indocumentada. Algunos trabajadores sin documentos llegan a los ranchos a pedir trabajo; pero la mayor parte son reclutados en México. Por lo tanto, son muchos los productores que dependen de uno o varios polleros para reclutar la mano de obra necesaria en la explotación. Cuando pierden a esta persona, porque decidió dejar esta actividad, fue detenido por las autoridades migratorias, o decidió trabajar para otro patrón, el empresario agrario queda en una situación de desamparo, sin brazos para cosechar unas producciones que son perecederas. En estas circunstancias, otro de sus trabajadores de confianza puede pasar a ejercer esta ocupación. Aunque la motivación principal de éstos para dedicarse a esta actividad tan arriesgada no es de carácter económico; sino el sentimiento de lealtad hacia una persona que les dio trabajo cuando llegaron por primera vez a un país extraño sin documentos. Como señalaba Teodoro:

"Yo hice esto, fue por la necesidad de que el que era quien llevaba a la gente, quien surtía la gente para trabajar, ya no quiso trabajar para el patrón, trabajó para otra persona que le pagó más que el patrón; por eso tuvimos la necesidad de que se trabajara así, de ese modo [...] No había quién llevara trabajadores, no había quién trabajara y ya teníamos todo el trabajo en puerta, y qué hacer, por eso ya sabía del camino yo, porque siempre fui de mojado, por eso era más fácil para mí que para otras personas; yo contaba con experiencia de años". 
Reinaldo se hizo pollero porque su hermano mayor se retiró de esta actividad, y él se sintió con la responsabilidad de sustituirle para ayudar a su patrón, que había sido muy bueno con su familia. Asimismo, Ramiro señaló que desde 2003 comenzó a trabajar como pollero porque ese año la policía federal de México detuvo a su amigo, que era el pollero de una compañía de semillas donde él trabajaba con una visa H-2A. Cuando éste fue detenido, él le sustituyó por lealtad hacia su amigo y también hacia el empleador que desde 2001 le ayudó a obtener su visa temporal de no inmigrante. 7

En casi ninguno de los casos hubo una reflexión sobre el riesgo y beneficios económicos derivados de dedicarse al coyotaje. Sin embargo, una vez dado el primer paso en el negocio del contrabando de indocumentados, tanto ellos como sus empleadores comprendieron que era una actividad que les reportaba beneficios. Los polleros obtienen un sobresueldo por cruzar la frontera una o más veces al año, y sus empleadores pueden abastecerse de mano de obra barata en momentos críticos; además, los migrantes transportados por los polleros son trabajadores dóciles: no son reivindicativos y no cuestionan los salarios. Como consecuencia, no es infrecuente que todos los gastos que acarrea el contrabando de migrantes sean asumidos por el empleador. Los patrones de Braulio, Melchor, Miguel, Ramiro, Rafael, Natalio, Reinaldo y Oliver pagaban todos los gastos y el resto cubrían una parte importante de los mismos. Aunque los empleadores siempre retoman la inversión que hicieron de las horas extraordinarias no pagadas que se verán obligados a hacer los migrantes o de la retención de éstos en los ranchos donde trabajan por un salario devaluado. Como decía Braulio "pagan trabajando con él y no yéndose con otro patrón [...] en un tiempo les paga menos que a los demás". Esta deuda puede extenderse por años; con ello los empleadores obtienen el aprecio y la gratitud de los inmigrantes, que pudieron emigrar porque su empleador financió su transporte; pero también su sumisión, ya que mientras no terminen de pagar la deuda contraída no pueden irse con otro empleador, que podría ofrecerles condiciones salariales más favorables.

Es así como surge una relación simbiótica entre los polleros y los empresarios agrarios. Los primeros dependen de los últimos para mantener sus ingresos, y los últimos de los primeros para incrementar la competitividad de sus explotaciones y recortar los costes de producción.

7 Aunque este entrevistado también admitió que la ganancia de 50 mil pesos por cruzar una vez al año la frontera con unos 15 indocumentados también influyó en su decisión de hacerse pollero, ya que sus gastos eran elevados debido a que consumía drogas. 
Los polleros son empleados muy capaces, que siempre demostraron una disposición para realizar cualquier actividad; en muchos casos todo lo que hacen gira en torno a la obligación de complacer a su empleador. Como señalaba Braulio: "a mi nada se me hace difícil, todo lo que se necesite lo hago, hasta de mecánico, chofer, cargador, y muchas cosas más [...]. Cuando él me encomienda una tarea yo le cumplo porque le cumplo, lo que él necesite yo lo hago, pues es el patrón". Como consecuencia, el empleador se torna dependiente de estos trabajadores tan eficientes, que le permiten disponer de una remesa constante de mano de obra dócil y barata. En este sentido, Ernesto señalaba que su patrón, un empresario agrario de Arkansas, le había dicho: "qué voy a hacer el día que ya no regreses; tú eres muy útil para mí". La permanente disponibilidad de los polleros hacia sus empleadores aparecía claramente expresada en el discurso de Eusebio "mi patrón si necesita me habla y así es como me tengo que ir por fuerza mayor y de rápido".

Una vez que los entrevistados se iniciaron en el coyotaje ya no hubo una vuelta atrás. Las siguientes expresiones hacen referencia a una inmersión progresiva en el negocio del contrabando de indocumentados. En un primer momento cruzaron la frontera acompañados de un grupo muy reducido de personas; después se corrió la voz en las localidades limítrofes y fueron cada vez más los que se acercaron a ellos para que les llevasen a los Estados Unidos; de este modo, el número de personas transportadas fue creciendo cada vez más.

“Así empezó esto. Sí llevo gente, no lo niego, pero sólo cuando vengo, o que allá me dicen: ve, voy y traigo gente" (Rafael).

“Así empezó esto [...] y después, los vecinos de ranchos colindantes me preguntaban que si sobraba gente que quisiera trabajar en los ranchos se las mandara y que me ganaría algo de dinero y así" (Óscar).

"Llevé primero tres que iban conmigo y ya después cada temporada que voy llevo 8 o 9, así fue como empecé" (Antonio).

"Me fui sólo con un compadre que había invitado y sí nos fue bien, esa fue en la primera vez, ya cuando vine al año y regresé me llevé a dos y al decir la tercera pues llevé como cinco y así pasó. Ahora que me vaya llevaré ocho, ya los tengo asegurados de que se van porque aquí no hay trabajo" (Carlos).

"Tuve la necesidad de ir y venir así seguido, y mejor opté por llevar gente para primero no ir solo y después para ganar un poco más, porque el dinero siempre se necesita, y así agarré colmillo, aprendí 
más y más con los años y también conocí más los caminos [...] y así me empecé a ser famoso y me fueron conociendo" (Osvaldo).

El incentivo económico no constituyó el elemento determinante para que ellos se dedicasen al coyotaje; sin embargo, la ganancia recibida por realizar esta actividad permitió que sus familias elevasen su nivel de vida. ${ }^{8}$ Aún así, la mayoría de los entrevistados colocan el aspecto económico en un segundo plano; en primer lugar aparece su disposición de servir a un patrón que siempre se ha portado bien con ellos. Reinaldo, un pollero de 28 años de edad de un ejido del municipio de Tula (Tamaulipas), que desde el 2003 cruza todos los años la frontera en enero con alrededor de 10 trabajadores que proceden de municipios cercanos a donde él reside, señalaba que él hacía esto para ayudar a su patrón, el dueño de una plantación de tabaco en Carolina del Norte, que primero dio trabajo a su padre, luego a sus dos hermanos mayores y más tarde también a él. Este entrevistado asumía el riesgo de realizar esta actividad como pago a su patrón por haber sacado a su familia de la pobreza. El dinero que él obtenía por realizar esta actividad, entre 5600 y 7000 dólares anuales, ${ }^{9}$ no constituía un incentivo suficiente para correr un riesgo tan alto; pero, dar la espalda a su empleador y no apoyarle con el reclutamiento de mano de obra sería algo inaceptable, porque se sentía obligado a devolver el favor a una persona que siempre fue buena tanto con él como con su familia.

"Él ya sabe que nosotros, la familia, siempre hemos trabajado para él, y que como él es buena gente con nosotros, nos da trabajo; entonces le ayudamos con eso de la gente".

\section{La presencia y actuación de las redes delictivas}

En Tamaulipas los contrabandistas de migrantes a mayor escala, que operan a tiempo completo, sobre todo las redes involucradas en el tráfico de centroamericanos, sufrieron desde los años noventa la extorsión de las autoridades; no así los contrabandistas a pequeña escala. Aunque estos últimos sí que sufrían ocasionalmente el ataque y despojo de sus pertenencias por

8 Las familias de los polleros que residen en el medio rural tamaulipeco se caracterizan por una situación económica superior a la media: viven en casas construidas con cemento y acero, tienen uno o más automóviles, muchos han invertido en tierras, ganado o en la apertura de pequeños negocios, y sus hijos presentan niveles de educación superiores a la media.

9 Su patrón cubría todos los gastos, incluidos los salarios de otras 6 personas que le ayudaban a llevar a los inmigrantes hasta Carolina del Norte. 
parte de pequeñas bandas desorganizadas de delincuentes que operaban en el territorio fronterizo. En Tamaulipas la delincuencia organizada no se interesó por el negocio del contrabando de migrantes hasta años más tarde; aunque en las áreas más meridionales del país la delincuencia organizada sí que descubrió años antes en el secuestro de migrantes una actividad lucrativa. La presencia de las redes delictivas en el contrabando de migrantes en Tamaulipas emergió en 2004. En un principio la actuación de los grupos delictivos se limitó al cobro de una pequeña cuota por cruzar el Río Bravo (Izcara Palacios, 2012a: 44). En aquel momento estos grupos se interesaron en las redes más grandes y sofisticadas que operaban de modo sistemático en la frontera; como contraste, durante los siguientes cuatro años los contrabandistas de migrantes a pequeña escala de Tamaulipas pudieron soslayar el yugo de la delincuencia organizada. Sin embargo, a partir del año 2008 una merma en los rendimientos del narcotráfico hizo que la delincuencia organizada en Tamaulipas buscase en la migración indocumentada una fuente estable y robusta de ingresos. Las redes delictivas contactaron uno por uno a aquellos contrabandistas más elusivos, que habían escapado a su radar, los que operaban a pequeña escala, y les obligaron a pagar un impuesto, que elevaron de modo periódico (Izcara Palacios, 2012b: 362). En un principio algunos contrabandistas se negaron a compartir sus ganancias con los delincuentes y se rehusaron a someterse a la disciplina impuesta por éstos; pero inmediatamente comprobaron que no seguir el dictado de la delincuencia organizada tendría consecuencias fatales. Como consecuencia, en el 2010 todos los contrabandistas de migrantes a pequeña escala de Tamaulipas ya habían aceptado que para sobrevivir debían renunciar a una parte de sus ingresos.

\section{Conclusión}

El contrabando de indocumentados a pequeña escala tiene una presencia importante en Tamaulipas, y constituye según los entrevistados la principal forma de reclutamiento de mano de obra en el sector agrario estadounidense. En muchos de los ejidos y comunidades rurales tamaulipecas es posible encontrar uno o varios polleros, a quienes todos conocen, que todos los años llegan una o más veces de los Estados Unidos para abastecer de mano de obra a sus empleadores.

A partir de los años noventa, como resultado del reforzamiento de la vigilancia de la frontera, algunos empresarios agrarios estadounidenses tomaron la iniciativa de reclutar indocumentados a través del envío pe- 
riódico a México de empleados de confianza en busca de mano de obra. Estos polleros son empleados de un empresario agrario estadounidense, para quien trabajaron por años antes de dedicarse al contrabando de migrantes. Una infancia dura, caracterizada por una temprana incorporación al mercado laboral para ayudar a sostener a una familia numerosa, inculcó en ellos una predisposición al riesgo, una ética del trabajo, un sentido de la lealtad, y una voluntad de sacrificio. Estas características pronto llamarían la atención de sus empleadores, con quienes forjaron lazos de amistad y confianza.

El contrabando de migrantes a pequeña escala en el sector agrario obedece al interés de los empleadores por abastecerse de mano de obra barata y disciplinada. Los polleros obtienen un beneficio económico por realizar esta actividad; sin embargo, en muchos casos estos ingresos extraordinarios no constituyen un incentivo suficiente. Ellos regresan periódicamente a Tamaulipas (entre una y cuatro veces al año) y asumen un riesgo elevado transportando migrantes porque se sienten en deuda con sus patrones, a quienes casi todos los entrevistados les describen como amigos. Por lo tanto, los responsables del contrabando de trabajadores migratorios no son los polleros, que no deciden ni el calendario (¿cuándo?) ni la intensidad (¿cuántos?) de esta actividad. Son sus empleadores quienes deciden cuándo, cuántos y qué migrantes deben ser transportados. Los jornaleros tamaulipecos tampoco emigran por iniciativa propia, ya que los empleadores dan a los polleros instrucciones precisas sobre las características de los trabajadores que deben reclutar. En el medio rural tamaulipeco la disposición de potenciales trabajadores es tan abundante que únicamente aquellos que cumplen con criterios muy estrictos serán conducidos al país del norte.

\section{Bibliografía}

Addiechi, Florencia, 2005, Fronteras reales de la globalización. Estados Unidos ante la migración latinoamericana, México, UACM.

Alonso Meneses, Guillermo, 2010, “De migras, coyotes y polleros. El argot de la migración clandestina en la región de Tijuana-San Diego", OGIGIA, núm. 8, pp. 15-31.

Andreas, Peter (2006) "Politics on Edge: Managing the US-Mexico Border", Current History, febrero, pp. 64-68. 
Andreas, Peter (2003) "A Tale of Two Borders: The US-Mexico and US-Canada Lines after 9-11", The Center for Comparative Immigration Studies. University of California, San Diego, Working Paper 77.

Arango, Joaquín, 2003, “La explicación teórica de las migraciones: Luces y sombras", Migración y Desarrollo, núm. 1, pp. 1-30.

Arango, Joaquín, 2000, “Explaining Migration: a Critical View”, International Social Science Journal, vol. 52, núm. 165, pp. 283-296.

Fuentes, Jezmín y García, Olivia ,2009, “Coyotaje: The Structure and Functioning of the People-Smuggling Industry", en Wayne A. Cornelius, David Fitzgerald y Scott Borger (eds.), Four Generations of Norteños. New Research from the Cradle of Mexican Migration, La Jolla, California, Center for Comparative Immigration Studies, pp. 79-100.

Gallagher, Anne, 2002, “Trafficking, Smuggling and Human Rights: Tricks and Treaties", Forced Migration Review, núm. 12, pp. 25-28.

García Vázquez, Nancy Janett, Elisa Gaxiola y Arnoldo Guajardo,2007, “Movimientos transfronterizos México-Estados Unidos: Los polleros como agentes de movilidad", Confines de Relaciones Internacionales y Ciencia Política, núm. 5, pp. 101-113.

Guerette, Rob T. y Ronald V. Clarke, 2005, “Border Enforcement, Organized Crime, and Deaths of Smuggled Migrants on the United States-Mexico Border", European Journal on Criminal Policy and Research, núm. 11, pp. 159-174.

House Committee on Homeland Security (HCHS), 2006, A Line in the Sand: Confronting the Threat at the Southwest Border, Subcommittee on Investigations.

Izcara Palacios, Simón Pedro, 2012a, "Coyotaje y grupos delictivos en Tamaulipas", Latin American Research Review, vol., 47, núm. 3, pp. 41-61.

Izcara Palacios, Simón Pedro, 2012b, "El declive del contrabando de indocumentados en México", Mexican Studies, vol. 28, núm. 2, pp. 351-376

Izcara Palacios, Simón Pedro, 2011, “Redes migratorias versus demanda laboral: Los elementos que moldean los procesos migratorios", Convergencia. Revista de Ciencias Sociales, vol. 18, núm. 57, pp. 39-59.

Izcara Palacios, Simón Pedro, 2010a, “La adicción a la mano de obra ilegal: Jornaleros tamaulipecos en Estados Unidos", Latin American Research Review, vol. 45, núm. 1, pp. 55-75. 
Izcara Palacios, Simón Pedro, 2010b, “Migración irregular y aislamiento social. Los jornaleros tamaulipecos indocumentados en los Estados Unidos", Revista Internacional de Sociología, vol. 68, núm. 2, pp. 453-472.

Izcara Palacios, Simón Pedro, 2010c, “Los factores no salariales en la migración internacional: El caso tamaulipeco", Revista de Ciencias Sociales, vol. 16, núm. 4, pp. 605-615.

Kyle, David y Dale, John (2001) "Smuggling the State Back In: Agents of Human Smuggling Reconsidered", en Kyle, David y Koslowski, Rey (eds.) Global Human Smuggling. Comparative Perspectives, Baltimore, The Johns Hopkins University Press, pp. 29-57.

Kyle, David y Zai Liand, 2001, "Migration Merchants: Human Smuggling from Ecuador and China", Working Paper, núm. 43, La Jolla, California, The Center for Comparative Immigration Studies.

López Castro, Gustavo, 1997, "Coyotes and Alien Smuggling”, en Binational Study: Migration between Mexico and the United States, vol. 3. U.S. Commission on Immigration Reform.

Martínez, Óscar, 2010, Los migrantes que no importan, Barcelona, Icaria Editorial.

Massey, Douglas S., Jorge Durand y Nolan J. Malone, 2009, Detrás de la trama. Políticas migratorias entre México y Estados Unidos, México, Miguel Ángel Porrúa.

Mestries Benquet, Francis, 2005, “Crisis agrícola y emigración en Veracruz", Comercio Exterior, vol. 55, núm. 12, pp. 1030-1041.

Nevins, Joseph, 2003, “Thinking out of Bounds: A Critical Analysis of Academic and Human Rights Writings on Migrant Deaths in the U.S.-Mexico Border Region", Migraciones Internacionales, vol. 2, núm. 2, pp. 171-190.

Sharma, Nandita (2005) "Anti-Trafficking Rhetoric and the Making of a Global Apartheid", NWSA Journal, 17 (3), pp. 88-111.

Schell, Greg, 2002, “Farmworker Exceptionalism under the Law. How the Legal System Contributes to Farmworker Poverty and Powerlessness", en C.D. Thompson y M.F. Wiggins (eds.), The Human Cost of Food. Farmworkers' Lives, Labor and Advocacy, University of Texas Press, Texas, pp. 139-168.

Sharma, Nandita, 2003, "Travel Agency: A Critique of Anti-Trafficking Campaigns", Refuge, vol. 21, núm. 3, pp. 53-65. 
Slack, Jeremy y Scott Whiteford, 2010, “Viajes violentos: La transformación de la migración clandestina hacia Sonora y California", Norteamérica, vol. 5, núm. 2, pp. 79-107.

Spener, David, 2009, Clandestine Crossings: Migrants and Coyotes on the Texas-Mexico Border, Ithaca, Nueva York, Cornwell University Press.

Spener, David, 2008, “El apartheid global, el coyotaje y el discurso de la migración clandestina: Distinciones entre violencia personal, estructural y cultural", Migración y Desarrollo, núm. 10, pp. 127-156.

Spener, David, 2004, “Mexican Migrant-Smuggling: A Cross-Border Cottage Industry", Journal of Internacional Migration and Integration, vol. 5, núm. 3, pp. 295-320.

Vayrynen, Raimio, 2003, "Illegal Immigration, Human Trafficking, and Organized Crime", Discussion Paper núm. 2003/72, Helsinki: UNO World Institute for Development Economics Research.

Zhang, Sheldon, 2010, "Get there Anyway you can. Human Smuggling to the U.S. and the Policy Implications", Policy Brief Series, núm. 8, Global Consortium on Security Transformation.

Zhang, Sheldon, 2007, Smuggling and Trafficking in Human Beings. All Roads Lead to America, Westport, Greenwood Publishing Group. 


\section{Anexo 1}

\section{Relación de los polleros entrevistados. Todos los municipios pertenecen al estado de Tamaulipas.}

\begin{tabular}{|c|c|}
\hline Jorge & $\begin{array}{l}\text { Entrevista realizada en abril de } 2008 \text { a un pollero de } 38 \text { años } \\
\text { de edad residente en el municipio de Victoria. }\end{array}$ \\
\hline Braulio & $\begin{array}{l}\text { Entrevista realizada en junio de } 2008 \text { a un pollero de } 39 \text { años } \\
\text { de edad residente en el municipio de Hidalgo. }\end{array}$ \\
\hline Mauro & $\begin{array}{l}\text { Entrevista realizada en junio de } 2008 \text { a un pollero de } 30 \text { años } \\
\text { de edad residente en el municipio de Ocampo. }\end{array}$ \\
\hline Melchor & $\begin{array}{l}\text { Entrevista realizada en junio de } 2008 \text { a un pollero de } 34 \text { años } \\
\text { de edad residente en el municipio de Victoria. }\end{array}$ \\
\hline Miguel & $\begin{array}{l}\text { Entrevista realizada en julio de } 2008 \text { a un pollero de } 29 \text { años } \\
\text { de edad residente en el municipio de Matamoros. }\end{array}$ \\
\hline Ramiro & $\begin{array}{l}\text { Entrevista realizada en julio de } 2008 \text { a un pollero de } 42 \text { años } \\
\text { de edad residente en el municipio de Victoria. }\end{array}$ \\
\hline Roberto & $\begin{array}{l}\text { Entrevista realizada en julio de } 2008 \text { a un pollero de } 40 \text { años } \\
\text { de edad residente en el municipio de Tula. }\end{array}$ \\
\hline Gerardo & $\begin{array}{l}\text { Entrevista realizada en julio de } 2008 \text { a un pollero de } 40 \text { años } \\
\text { de edad residente en el municipio de San Fernando. }\end{array}$ \\
\hline Tomás & $\begin{array}{l}\text { Entrevista realizada en octubre de } 2008 \text { a un pollero de } 45 \text { años } \\
\text { de edad residente en el municipio de Hidalgo. }\end{array}$ \\
\hline Rafael & $\begin{array}{l}\text { Entrevista realizada en octubre de } 2008 \text { a un pollero de } 43 \text { años } \\
\text { de edad residente en el municipio de Reynosa. }\end{array}$ \\
\hline Natalio & $\begin{array}{l}\text { Entrevista realizada en octubre de } 2008 \text { a un pollero de } 27 \text { años } \\
\text { de edad residente en el municipio de El Mante. }\end{array}$ \\
\hline Zacarías & $\begin{array}{l}\text { Entrevista realizada en noviembre de } 2008 \text { a un pollero de } 45 \text { años } \\
\text { de edad residente en el municipio de Reynosa. }\end{array}$ \\
\hline Oliver & $\begin{array}{l}\text { Entrevista realizada en noviembre de } 2008 \text { a un pollero de } 33 \text { años } \\
\text { de edad residente en el municipio de Matamoros. }\end{array}$ \\
\hline Orencio & $\begin{array}{l}\text { Entrevista realizada en noviembre de } 2008 \text { a un pollero de } 35 \text { años } \\
\text { de edad residente en el municipio de Tula. }\end{array}$ \\
\hline Prudencio & $\begin{array}{l}\text { Entrevista realizada en noviembre de } 2008 \text { a un pollero de } 40 \text { años } \\
\text { de edad residente en el municipio de Jaumave. }\end{array}$ \\
\hline Reinaldo & $\begin{array}{l}\text { Entrevista realizada en diciembre de } 2008 \text { a un pollero de } 28 \text { años } \\
\text { de edad residente en el municipio de Tula. }\end{array}$ \\
\hline Ernesto & $\begin{array}{l}\text { Entrevista realizada en diciembre de } 2008 \text { a un pollero de } 42 \text { años } \\
\text { de edad residente en el municipio de El Mante. }\end{array}$ \\
\hline Eusebio & $\begin{array}{l}\text { Entrevista realizada en diciembre de } 2008 \text { a un pollero de } 39 \text { años } \\
\text { de edad residente en el municipio de Tula. }\end{array}$ \\
\hline Óscar & $\begin{array}{l}\text { Entrevista realizada en enero de } 2009 \text { a un pollero de } 36 \text { años } \\
\text { de edad residente en el municipio de Matamoros. }\end{array}$ \\
\hline Rodolfo & $\begin{array}{l}\text { Entrevista realizada en enero de } 2009 \text { a un pollero de } 41 \text { años } \\
\text { de edad residente en el municipio de Mier. }\end{array}$ \\
\hline Teodoro & $\begin{array}{l}\text { Entrevista realizada en febrero de } 2009 \text { a un pollero de } 45 \text { años } \\
\text { de edad residente en el municipio de Miquihuana. }\end{array}$ \\
\hline Teófilo & $\begin{array}{l}\text { Entrevista realizada en febrero de } 2009 \text { a un pollero de } 38 \text { años } \\
\text { de edad residente en el municipio de Jaumave. }\end{array}$ \\
\hline Valerio & $\begin{array}{l}\text { Entrevista realizada en febrero de } 2009 \text { a un pollero de } 32 \text { años } \\
\text { de edad residente en el municipio de Tula. }\end{array}$ \\
\hline Antonio & $\begin{array}{l}\text { Entrevista realizada en febrero de } 2009 \text { a un pollero de } 33 \text { años de edad residente en el } \\
\text { municipio de Reynosa. }\end{array}$ \\
\hline
\end{tabular}




\begin{tabular}{|c|c|c|}
\hline \multirow{4}{*}{ 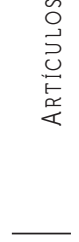 } & Carlos & $\begin{array}{l}\text { Entrevista realizada en febrero de } 2009 \text { a un pollero de } 40 \text { años } \\
\text { de edad residente en el municipio de Reynosa. }\end{array}$ \\
\hline & Abelardo & $\begin{array}{l}\text { Entrevista realizada en abril de } 2009 \text { a un pollero de } 49 \text { años } \\
\text { de edad residente en el municipio de San Fernando. }\end{array}$ \\
\hline & Vicente & $\begin{array}{l}\text { Entrevista realizada en abril de } 2009 \text { a un pollero de } 48 \text { años } \\
\text { de edad residente en el municipio de Abasolo. }\end{array}$ \\
\hline & Lucio & $\begin{array}{l}\text { Entrevista realizada en abril de } 2009 \text { a un pollero de } 30 \text { años } \\
\text { de edad residente en el municipio de Abasolo. }\end{array}$ \\
\hline \multirow{6}{*}{ 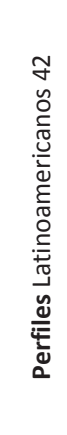 } & Francisco & $\begin{array}{l}\text { Entrevista realizada en abril de } 2011 \text { a un pollero de } 39 \text { años } \\
\text { de edad residente en el municipio de San Carlos. }\end{array}$ \\
\hline & Tadeo & $\begin{array}{l}\text { Entrevista realizada en abril de } 2011 \text { a un pollero de } 38 \text { años } \\
\text { de edad residente en el municipio de Victoria. }\end{array}$ \\
\hline & Basilio & $\begin{array}{l}\text { Entrevista realizada en abril de } 2011 \text { a un pollero de } 44 \text { años } \\
\text { de edad residente en el municipio de Victoria. }\end{array}$ \\
\hline & Uriel & $\begin{array}{l}\text { Entrevista realizada en mayo de } 2011 \text { a un pollero de } 35 \text { años } \\
\text { de edad residente en el municipio de Victoria. }\end{array}$ \\
\hline & Antonio & $\begin{array}{l}\text { Entrevista realizada en septiembre de } 2011 \text { a un pollero de } 33 \text { años } \\
\text { de edad residente en el municipio de Reynosa. }\end{array}$ \\
\hline & Rubén & $\begin{array}{l}\text { Entrevista realizada en septiembre de } 2011 \text { a un pollero de } 46 \text { años } \\
\text { de edad residente en el municipio de Tula. }\end{array}$ \\
\hline \multirow{7}{*}{134} & Sergio & $\begin{array}{l}\text { Entrevista realizada en septiembre de } 2011 \text { a un pollero de } 39 \text { años } \\
\text { de edad residente en el municipio de Victoria. }\end{array}$ \\
\hline & Bonifacio & $\begin{array}{l}\text { Entrevista realizada en octubre de } 2011 \text { a un pollero de } 43 \text { años } \\
\text { de edad residente en el municipio de Victoria. }\end{array}$ \\
\hline & Horacio & $\begin{array}{l}\text { Entrevista realizada en diciembre de } 2011 \text { a un pollero de } 30 \text { años } \\
\text { de edad residente en el municipio de Hidalgo. }\end{array}$ \\
\hline & Misael & $\begin{array}{l}\text { Entrevista realizada en diciembre de } 2011 \text { a un pollero de } 29 \text { años } \\
\text { de edad residente en el municipio de Palmillas. }\end{array}$ \\
\hline & Néstor & $\begin{array}{l}\text { Entrevista realizada en diciembre de } 2011 \text { a un pollero de } 32 \text { años } \\
\text { de edad residente en el municipio de Tula. }\end{array}$ \\
\hline & Osvaldo & $\begin{array}{l}\text { Entrevista realizada en diciembre de } 2011 \text { a un pollero de } 40 \text { años } \\
\text { de edad residente en el municipio de Tula. }\end{array}$ \\
\hline & \multicolumn{2}{|c|}{ Nota: Los nombres son seudónimos. } \\
\hline
\end{tabular}

Recibido el 3 de enero de 2012

Aceptado el 27 de abril de 2013 